\title{
Non-descent Vaginal Hysterectomy: Safety and Feasibility
}

\author{
Saha R, Shrestha NS, Thapa M, Shrestha J, Bajracharya J, Padhye SM \\ Department of Obstetrics and Gynecology Kathmandu Medical College Teaching Hospital, Kathmandu, Nepal
}

Aims: To assess safety and feasibility of non-descent vaginal hysterectomy.

Methods: A hospital based prospective study was conducted at the department of obstetrics and gynecology of Kathmandu Medical College Teaching Hospital from 1st January 2010 to 31st December 2011. All the patients undergoing non -descent vaginal hysterectomy for benign indication, without suspected adnexal pathology were included in the study. Vaginal hysterectomy was done in usual manner. In bigger size uterus morcellation techniques like bisection, debulking, myomectomy, slicing, or combination of these were used to remove the uterus. Data regarding age, parity, uterine size ,estimated blood loss, length of operation, complication and hospital stay were recorded.

Results: A total of 50 cases were selected for non-descent vaginal hysterectomy. Among them 43 cases successfully underwent non-descent vaginal hysterectomy. Commonest age group was (41-45 years) i.e. 40\%. All patients were parous. Uterus size was $<10$ weeks in 27 cases and $>10$ weeks in 23 cases. Commonest indication was leiomyoma of uterus (63\%). Mean duration of surgery was two hours. Mean blood loss was $205.26 \mathrm{ml}$. Reasons for failure to perform NDVH was difficulty in opening pouch of Douglas in three cases. In rest of four cases there was difficulty in reaching the myoma and transverse diameter was too large so as to prevent descent of the uterus. The most common complication was post -operative pain in $23 \%$ of cases. Febrile morbidity was present in $4.6 \%$ of cases. Blood transfusion was required in seven cases. Average duration of hospital stay was three days.

Conclusions: Vaginal hysterectomy for benign gynecological causes other than prolapse is safe and feasible. For successful outcome size of uterus, size in all dimensions and location of fibroid should be taken into consideration.Today in the era of minimally invasive surgery, non descent vaginal hysterectomy needs to be considered and seems to be a safe option.

Keywords: Feasibility, non -descent vaginal hysterectomy, safety.

\section{INTRODUCTION}

Hysterectomy is the commonest major surgical procedure performed in gynecology. Traditionally various routes for removal of uterus have been used. Abdominal hysterectomy is undoubtedly the most popular with a 70:30 ratio for abdominal versus vaginal route. ${ }^{1,2,3}$ It was the introduction of laparoscopic hysterectomy in particular, that has ignited the comparison between different routes and techniques. The latest VALUE STUDY concluded that major hemorrhage, hematoma, ureteric injury, bladder injury, and anesthetic complications were more in laparoscopic assisted hysterectomy (LAVH) group when compared to abdominal and vaginal hysterectomies. In addition LAVH was accomplished in twice the time required for vaginal hysterectomy. ${ }^{1,2}$ Similarly CREST STUDY and numerous case series reviews have supported the fact that there is significant reduction in complication rate in vaginal route than abdominal and recommended vaginal route as the primary route. This paper aims at sharing experience of first 50 cases of non- descent vaginal hysterectomy and exploring the safety and feasibility of non-descent vaginal hysterectomy in disease confined to the uterus at Kathmandu Medical College Teaching hospital.

\section{CORRESPONDENCE}

Dr Rachana Saha, MD

Associate Professor

Department of Obstetrics and Gynecology

Kathmandu Medical College Teaching Hospital,

Kathmandu, Nepal

Phone: 9841241296

Email: rachana_saha@yahoo.com 


\section{METHODS}

A hospital based prospective study was conducted from 1st January 2010 to 31st December 2011. All the patients undergoing non descent vaginal hysterectomy for benign indications, without suspected adnexal pathology were taken for study. Prerequisites for non descent vaginal hysterectomy (NDVH) were set as uterine size not exceeding 20 weeks of gravid uterus (by clinical judgment) and adequate vaginal access with good uterine mobility. Exclusion criteria included uterus with restricted mobility, suspicion of malignancy and complex adnexal masses. Special consent for conversion to abdominal hysterectomy if needed, was taken. All cases were reassessed in operating theater after the patient was anesthetised, to confirm the size, mobility of uterus, vaginal accessibility, and laxity of pelvic muscles. Vaginal hysterectomy was considered successful if it was not abandoned or converted to abdominal route. In bigger size uterus morcellation techniques like uterine bisection, debulking, myomectomy or combinations of these were performed as and when required. Data regarding age, parity, uterine size, estimated blood loss, length of operation, complications and hospital stay were recorded. All patients received prophylactic antibiotics for 5 days. Post operative Foley catheter was kept in all cases for 24 hours. All patients were followed from time of admission to time of discharge and 2 weeks thereafter.

\section{RESULTS}

Total no. of cases contemplated for NDVH during the study period was 50 . NDVH was successfully performed in 43 cases whereas seven cases had to be completed through abdominal route due to various reasons. Mean duration of surgery was 2 hours. Mean blood loss was $205.26 \mathrm{ml}$.

\section{Table 1. Indications for NDVH}

\begin{tabular}{lcl}
\hline Indications & No. & Percentage \\
\hline Fibroid uterus & 23 & $46 \%$ \\
DUB & 13 & $26 \%$ \\
Adenomyosis & 12 & $24 \%$ \\
Cervical polyp & 1 & $2 \%$ \\
HSIL & 1 & $2 \%$ \\
Total & 50 & 100 \\
\hline
\end{tabular}

*commonest indication was fibroid uterus

Table 2. Age group of the patients

\begin{tabular}{lcl}
\hline Age group (yrs) & No. & Percentage \\
\hline $35-40$ & 15 & $30 \%$ \\
$41-45$ & 20 & $40 \%$ \\
$46-50$ & 5 & $10 \%$ \\
$>50$ & 10 & $20 \%$ \\
Total & 50 & 100 \\
\hline
\end{tabular}

*commonest age group was 41-45 yrs
Table 3. Parity of the patients

\begin{tabular}{lcl}
\hline Parity & No. & Percentage (\%) \\
\hline 1 & 3 & $6 \%$ \\
2 & 25 & $50 \%$ \\
3 & 10 & $20 \%$ \\
4 & 12 & $24 \%$ \\
Total & 50 & 100 \\
\hline
\end{tabular}

*most of the patients were para 2

Table 4. Uterine size in cases selected for NDVH

\begin{tabular}{ll}
\hline Uterine size & Cases \\
\hline Normal to 6 weeks & 15 \\
$>6$ to 10 weeks & 12 \\
$>10$ to 12 weeks & 8 \\
$>12$ to 16 weeks & 12 \\
$>16$ to 20 weeks & 2 \\
Total cases & 50 \\
\hline
\end{tabular}

*majority of cases had less than 10 weeks size uterus

Table 5. Debulking techniques used

\begin{tabular}{ll}
\hline Technique & Cases \\
\hline Bisection & 43 \\
Myomectomy & 19 \\
Morcellation (slicing and wedge debulking) & 5 \\
\hline *combination of these techniques required in some cases \\
Table 6. Reasons for abandonment of NDVH
\end{tabular}

\begin{tabular}{ll}
\hline Reasons & Cases \\
\hline $\begin{array}{l}\text { Difficulty in opening pouch of Douglas (due } \\
\text { to adhesion of endometriosis) }\end{array}$ & 3 \\
$\begin{array}{l}\text { Transverse diameter of uterus being too } \\
\text { large and difficulty in reaching myoma }\end{array}$ & 4 \\
\hline Table 7. Complications in cases of NDVH & \\
\hline Complications & No. \\
\hline Post operative pain & 10 \\
Fever & 2 \\
Hemorrhag requiring transfusion & 7 \\
\hline
\end{tabular}

\section{DISCUSSION}

Out of 50 cases selected for NDVH, 43 cases were completed successfully, whereas seven cases were converted to abdominal hysterectomy due to various reasons. Majority of the patients were in the age group of 41-45 year. Similar age prevalence was noted in other case series reviews. ${ }^{3-8}$ Similarly most of the patients were parous comparable to other studies. ${ }^{3,4,5,6,11}$ The commonest indication was fibroid uterus (46\%). Leiomyoma of uterus remained commonest indication in case series by Goel et $\mathrm{al}^{3}{ }^{3}$ Dewan et al ${ }^{4}$, Bharatnur et $\mathrm{al}^{5}$ and Singh et al. ${ }^{7}$ 
In our study no single case had earlier undergone abdominal pelvic surgery. Mean blood loss was $205.26 \mathrm{ml}$ and amount of loss depend on uterine size and duration of surgery. It was lesser than that reported in other studies like $268 \mathrm{ml}^{3}$, $290 \mathrm{ml}^{4}, 316.4 \mathrm{ml} .{ }^{5}$ But it was more as compared to some other studies as $100 \mathrm{ml}^{6}$ and $35.56 \mathrm{ml} .{ }^{7}$ Seven $(15 \%)$ of the patients required blood transfusion which is double than shown by CREST study. Mean duration of surgery was 2 hours as compared to Goel et al (64 minutes), ${ }^{3}$ Dewan et al $(54.5 \text { minutes })^{4}$,Bharatnur et al $(65 \text { minutes })^{5}$ and Bhadra (55 minutes). ${ }^{6}$ The operative time was definitely more in the earlier phase of the learning curve. It was also dependent on the size of uterus. Same was noted by Seth in his personal series of 5655 cases. ${ }^{1,2}$ In present study on analyzing the failed cases, there was difficulty in opening pouch of Douglas due to adhesions in three cases. On opening abdomen there was puckering and obliteration of pouch of Douglas because of endometoriosis. In rest of four cases there was difficulty in reaching the myoma and transverse diameter being large so as to prevent descent. Similar reasons were cited by $\mathrm{Goel}^{3}$ in their analysis of 75 cases. Hence dimensions of uterus in both anterio-posterior and transverse direction should be taken into account. Debulking was done in all cases. Among all the debulking surgeries bisecting the uterus remained

\section{REFERENCES}

1. Sheth SS. Vaginal hysterectomy.In: PuriR, Malhotra N. eds. Operative Obstetrics and Gynaecology. New Delhi. Jaypeebrother's medical publishers.2009:499-510.

2. Sheth SS, Paghdiwalla K P. In: Saraiya UB, Rao A K, Chateerjee A.eds .Principles and Practice of obstetrics and Gynaecology.2nd ed.New Delhi. Jaypee brothers medical publishers.2003.374-30.

3. Goel N, Rajaram S, Ghumman S.eds .Step by Step Non-Descent vaginal hysterectomy.New Delhi. Jaypee brothers medical publishers.

4. Dewan R, Agarwal S, Minocha B, Sen SK. Non-descent Vagina Hysterectomy -An Experience . J Obstet Gynecol Ind .2004;54(4):3768.

5. Bharatnur S. Comparative study of abdominal versus vaginal hysterectomy in Non-Descent cases.The internet journal of Gynaecology and Obstetrics .2011;15(2):1528-8439.

6. Bhadra B, Choudary AP, Tolassaria A, Nupur N. Non-Descent Vaginal hysterectomy (NDVH): Personal experiences in 158 cases. AL Ameen J Med Sci. 2011;4(1):23-7.

7. Singh A, Bansal S. Comparative study of morbidity and mortality associated with Non- descent Vaginal hysterectomy based on ultra sonographic determination of uterine volume. IntSurg 2008;93(2):88-94. the first and foremost technique. ${ }^{3}$ Major complications were nil. This series included well selected cases and was operated by surgeons who had long experience in vaginal hysterectomy. Complications were minimal which included post-operative pain and fever.

\section{CONCLUSIONS}

A thorough pre-operative assessment and examination under anesthesia is an integral part of decision making for route of hysterectomy. Size, descent and mobility of uterus, uterine dimensions along with fundal height should be considered before contemplating nondescent vaginal hysterectomy. Debulking is safe and accomplishes the surgery by vaginal route in most of the cases. NDVH is safe and feasible in hands of trained vaginal surgeons. Decision for route of hysterectomy should be individualized depending upon what is best for the patient. If hysterectomy is possible by all three routes, preference should be given to vaginal route. Patient should also know the best options available and be involved in decision making.

8. Kovac SR. Hysterectomy outcomes in patients with similar indications Obstet Gynecol .2000;95:787-93.

9. Dorsey $\mathrm{JH}$,Steinberg EP,Holtz PM.Clinical indications for hysterectomy route:patients characteristic or physician preference.AM J Obstet Gynecol. 1996;175(1):232-3

10. Cardosi. J.Richard. Determining the best route for hysterectomy .The journal of family practice .July 2002;14(7): ??

11. Dicker RC, Greenspan JR, Strauss LT etal. Complications of vaginal and abdominal hysterectomy among women of reproductive age in the United States. Am J Obstet G ynecol.982;144; 841-8.

12. Geoff. McCracken, Guylaine G. Lefebvre I. Vaginal hysterectomy Dispelling the myths. JOGC 2007;424-7.

13. Chakraborty S, Goswami S, Mukherjee P, SauM. Hysterectomy... which route. Journal of Obstet and Gynecol of India. 2012;61(5):554-7.

14. Royal KK,Goyal MM

, Singh S, Malhotran N, Kumar S. Archives of Gynaecology. 2011;284(4);90712 